\title{
PAWEES 2008 international conference on benefit of paddy to sustainable development: first announcement
}

\author{
Ching-Pin Tung
}

Received: 15 January 2008/Accepted: 15 January 2008/Published online: 7 February 2008

(C) Springer-Verlag 2008

\section{Scope of conference}

The aim of this conference is twofold: a) information sharing of most recent researches on effectual technologies; and b) their application to sustainable water management in paddy fields. The conference will have four sessions:

1. Paddy and Food Security, Social Justice, Economic Development

2. Paddy and Natural Disaster Mitigation

3. Paddy and Climate Change

4. Paddy and Sustainable Water Environment

The conference will bring together leading players, in the relevant fields, representing academia and international authorities including experienced engineers. Our international view will be enriched by: presentations of the latest study results and information exchange; pulling out future priority subjects in the field of paddy and water environment; discussing the future direction of international research; deliberating on several methodologies for application of past research achievements to the current and real world; and exploring strategies for food security, eradication of poverty and hunger in developing countries, and the development of agricultural communities.

\section{Call for papers}

Conference participants who wish to make oral presentations are invited to submit papers on various topics under the following four thematic areas:

C.-P. Tung $(\bowtie)$

Department of Bioenvironmental Systems Engineering,

National Taiwan University, Taipei 10617, Taiwan

e-mail: cptung@ntu.edu.tw
1. Paddy and Food Security, Social Justice, Economic Development

2. Paddy and Natural Disaster Mitigation

3. Paddy and Climate Change

4. Paddy and Sustainable Water Environment

\section{Instruction for authors}

Authors are requested to submit abstracts of their papers via E-mail (cptung@ntu.edu.tw), as an attachment in MS word format. The abstract should not be more than 250 words excluding the title of the paper, author name(s), affiliation(s), and keyword(s) that should be displayed at the top of the page.

The science committee of the conference will decide on the acceptance or non-acceptance of the abstracts for presentation. The selected authors will be requested to submit the completed paper via E-mail to the same address. Instructions for preparation of full papers will be announced on the conference website by the time of completion of paper selection. Submitted full papers will be published in conference proceedings.

\section{Conference language}

English

\section{Date and location}

Monday, October 27-Wednesday, October 29, 2008 International Conference Hall of Leader Hotel, National Taiwan University, Taipei, Taiwan 


\section{Important dates}

Submission of abstract: by May 10th, 2008

Submission of full paper: by September 30th, 2008

Registration deadline: October 25th, 2008

\section{Program}

PAWEES International Conference: October 27th, 2008

PAWEES Award Ceremony and Annual Meeting: October 28th, 2008

Technical Tour: October 29th, 2008

\section{Registration}

Registration period: July 25th to October 25th, 2008

On-site registration might be accepted conditionally.

Registration fee: 3500 NTD or US\$100

Early registration (by August 25th, 2008): 1570 NTD or US\$50

The registration fee will be paid on October 27 th or 28 th at the registration desk of the conference site. The conference proceedings will be given at the registration desk.

\section{Accommodations}

The organizer will provide information on appropriate hotels in Taipei, details of which will be available later on the conference website.

\section{Contacts}

Professor Ching-Pin Tung

Department of Bioenvironmental Systems Engineering, National Taiwan University Taipei 10617, Taiwan

Phone: +886-2-33663461, Fax: +886-2-23635854, E-mail: cptung@ntu.edu.tw

\section{Regional contact}

Dr. Nasir M. Khan, Scientific Coordination Officer of the Secretariat, Nippon Giken Inc. Islamabad Office House No. 203, Street No. 74, Sector I-8/3, Islamabad, Pakistan

E-mail: nasirng@comsats.net.pk,kmnasir97@yahoo.com 